\title{
Radiation dosimetry of
}

\section{Tc-99m-PSMA I\&S: a single-center prospective study}

Szabolcs Urbán ${ }^{1}$, Catherine Meyer2,3, Magnus Dahlbom2,3, István Farkas ${ }^{1}$, Gábor Sipka ${ }^{1}$, Zsuzsanna Besenyi ${ }^{1}$, Johannes Czernin2,4,5, Jeremie Calais2,3,4,5 *, László Pávics ${ }^{1}$ *

1. Department of Nuclear Medicine, University of Szeged, Szeged, Hungary

2. Ahmanson Translational Theranostics Division, Department of Molecular and Medical Pharmacology, University of California Los Angeles, Los Angeles, CA, USA

3. Physics \& Biology in Medicine Interdepartmental Graduate Program, David Geffen School of Medicine, University of California Los Angeles, Los Angeles, CA, USA

4. Jonsson Comprehensive Cancer Center, University of California Los Angeles, Los Angeles, CA, USA

5. Institute of Urologic Oncology, University of California Los Angeles,

Los Angeles, Los Angeles, CA, USA

* These 2 authors contributed equally to this work

Corresponding author: Szabolcs Urbán,

Department of Nuclear Medicine,

University of Szeged, H-6720 Szeged, Korányi fasor 6., Hungary.

Telephone number: +3662545375

E-mail: urban.szabolcs@med.u-szeged.hu

Word count: 4829 words

Short title: Dosimetry of Tc-99m-PSMA I\&S

Key words: dosimetry, Tc-99m-Mas3-y-nal-k(Sub-KuE), PSMA I\&S, Prostate cancer, SPECT/CT 


\section{ABSTRACT}

Introduction: Tc-99m-labeled Mas3-y-nal-k(Sub-KuE) (Tc-99m-PSMA I\&S) is a prostate specific membrane antigen (PSMA) tracer that can be used for planar and SPECT/CT gamma imaging and radioguided surgery (RGS). The primary aim of this study was to estimate the dosimetry of Tc-99m-PSMA I\&S using a hybrid method (sequential gamma planar imaging and one single SPECT/CT) in healthy volunteers. The secondary aim was to depict the tracer biodistribution and tumor-to-background ratios (TBR) in patients with prostate cancer (PCa). Methods: Dosimetry of Tc-99m-PSMA I\&S was investigated in four healthy volunteers. Whole-body planar imaging was acquired at 1, 2, 3, 6 and 24 hours, and SPECT/CT at 6h after tracer injection. Contours of organs were drawn on all acquisitions to determine organ activity at each timepoint. Absorbed dose was estimated using two methods: 1) independent curve-fitting manual method (Levenberg-Marquardt-based algorithm using dose factors from Radiation Dose Assessment Resource (RADAR) web site) and 2) OLINDA/EXM® v 2.0 software (HERMES Medical Solutions). Biodistribution of Tc-99m-PSMA I\&S was assessed in ten patients with PCa on SPECT/CT images at $6 \mathrm{~h}$. Tumor uptake (SUVmax), and TBR (tumor SUVmax/ background organ SUVmean) using muscle (T/M), bladder (T/B) and intestine (T/I) as background organs were determined. Results: The mean injected activity of Tc-99m-PSMA I\&S was 717 MBq (range: 562-828). No adverse events related to the injection of Tc-99m-PSMA-I\&S were reported. The average radiation effective dose was $0.0055 \mathrm{mSv} / \mathrm{MBq}$ with the RADAR manual method and $0.0052 \mathrm{mSv} / \mathrm{MBq}$ with OLINDA/EXM ${ }^{\circledR}$. Total body effective dose ranged between 3.33-4.42 and 3.11-4.23 mSv, respectively. All PCa patients showed high tracer uptake in primary and metastatic lesions with $\mathrm{T} / \mathrm{M}, \mathrm{T} / \mathrm{B}, \mathrm{T} / \mathrm{I}$ ranging from $5.29-110,0.11-7.02$ and $0.96-16.30$, respectively. Conclusion: Effective doses of Tc-99m-PSMA I\&S were comparable to those known for most of the Tc-99m tracers and was lower than 68Ga-labelled and 18F-labelled agents. Tc-99m-PSMA I\&S SPECT/CT showed high TBR in PCa patients. This study can provide required data for translation and approval of Tc-99m-PSMA I\&S by regulatory agencies. 


\section{INTRODUCTION}

Prostate-specific membrane antigen (PSMA) is a transmembrane metallopeptidase protein highly overexpressed on the surface of prostate cancer (PCa) cells thus representing a relevant target for PCa nuclear theranostics (1). In the past decade, hundreds of thousands of PSMA PET scans have been performed worldwide for staging and restaging $\mathrm{PCa}$, reflecting the rapid and profound clinical adoption by the uro-oncologist community. Technetium- $99 \mathrm{~m}$ is the most widely-used radionuclide for diagnostic imaging; therefore, Tc-99m-labelled PSMA compounds could be a valuable cost-effective alternative in regions where access to PSMA-PET imaging is limited. Tc-99m-PSMA imaging can also enable radioguided surgery (RGS) with intra-operative gamma detection. PSMA-targeted RGS can help and guide urologists to detect PCa lymph node (LN) metastasis during surgery. Different Tc-99m-PSMA compounds have been developed. Tc-99m-Mas3-y-nal-k(Sub-KuE) (Tc-99m PSMA I\&S) is a non-patented compound derived from the PSMA I\&T precursor that can be obtained with a reliable kit-labeling procedure (2). Previous work has shown the utility of Tc-99m-PSMA I\&S for RGS in large retrospective cohorts with

improved treatment outcome $(3,4)$. As a required step for further translation and approval by regulatory agencies, the primary objective of this study was to provide the radiation dosimetry analysis of Tc-99mPSMA I\&S in healthy volunteers using a hybrid imaging method (sequential gamma planar imaging and one single SPECT/CT). The secondary aim was to describe the biodistribution of Tc-99m-PSMA I\&S in PCa patients at 6 hours after tracer injection.

\section{MATERIALS AND METHODS}

\section{Study Design and Patients}

This is a prospective study of radiation dosimetry and biodistribution of a novel Tc-99m-PSMA imaging probe. The study protocol was approved by the local institutional ethics committee for human biomedical trials at the University of Szeged (license number 229/2017-SZTE, date of approval 20-Nov-2017). The imaging data acquisition was performed at the University of Szeged, in Hungary. Four healthy men 
clinically free from any malignant disease were enrolled in the dosimetry study. Ten patients with newly diagnosed PCa were enrolled in the biodistribution study. All patients provided oral and written consent after receiving detailed information of the study and agreed to the collection of data. The analysis was conducted at the University of Szeged in Hungary and at the University of California in Los Angeles, USA (material transfer agreement MTA2020-00000538).

\section{Synthesis and Quality Control of Tc-99m-PSMA I\&S}

Synthesis of Mas3-y-nal-k(Sub-KuE) peptide-lyophilisate has been previously reported (2). Tc-99mpertechnetate was obtained from a Mo99/Tc-99m generator. A single-dose freeze-dried kit contains $25 \mu \mathrm{g}$ of peptide. Radiolabelling were performed with 5.87 - 7.53 GBq of Tc-99m-pertechnetate. Radiochemical purity analysis was performed by Instant Thin Layer Chromatography Medium paper impregnated with a silica gel. As a solvent we used Methyl-Ethyl-Ketone. Radiochemical purities were in all cases greater than $95 \%$.

\section{Image Acquisition}

A hybrid imaging method was used to determine the dosimetry of Tc-99m PSMA I\&S: multiple time-point whole-body (WB) planar imaging and one single quantitative SPECT/CT scan. In all healthy subjects (n=4) WB anterior and posterior scintigraphy was performed at 1, 2, 3, 6 and $24 \mathrm{~h}$ after radiopharmaceutical administration (Figure 1) using a triple head gamma camera (AnyScan Trio SPECT/CT, Mediso Medical Imaging Systems Ltd.), equipped with low energy, high-resolution collimators (LEHR). The scanning speed was $18 \mathrm{~cm} / \mathrm{min}$, matrix size of $256 \times 1024$ pixels was used and a symmetric $20 \%$ window was set at $140 \mathrm{keV}$. In all volunteers and PCa patients ( $\mathrm{n}=14$ ) whole-body (mid-thighs to vertex) SPECT/CT images were acquired at $6 \mathrm{~h}$ after radiopharmaceutical administration (Figure 2). Quantitative SPECT images were acquired using a $128 \times 128$ matrix with a $20 \%$ energy window centered at $140 \mathrm{keV}$ with adjacent scatter correction windows. A total of 96 projection views were acquired over 360 degrees in 3.75 degree steps at 10 s per view. The number of bed positions was 3 . Reconstruction of raw SPECT data was carried out using 
the iterative Tera-Tomo (Mediso Medical Imaging Systems Ltd.) software which is based on the order of sets and subsets (48 iterations/4 subsets) method. CT-based attenuation correction and Point Spread Function (PSF) correction were used. CT images were acquired using low dose CT $(120 \mathrm{KeV}, 100 \mathrm{mAs}$, 1.5 pitch factor and $2.5 \mathrm{~mm}$ slice thickness). To improve the visibility of the gastrointestinal tract, Macrogol 1500 (50g/l) was administered orally one hour before SPECT/CT imaging.

\section{Determination of Absorbed Doses}

The source organs consisted of the salivary glands, kidneys, liver, small intestine, large intestine, spleen, urinary bladder, and the body remainder. Source organs contours and appropriate background regions-ofinterest (ROIs) were delineated manually on the anterior and posterior WB images at $1 \mathrm{~h}$ after injection (example in Figure 1). All ROIs were manually relocated on the subsequent images and were validated by two experienced nuclear medicine physicians (ZsB and LP).

The mean counts were obtained for each organ and background ROI. Background corrected organ counts were then calculated (based on the number of pixels from the organ ROI) for both anterior and posterior WB images. The geometric mean count was determined for every organ from the background-corrected anterior and posterior counts.

Source organ volumetric contours were delineated manually on CT images. The volumes-of-interest (VOIs) were transferred to the registered quantitative SPECT scans to determine the activity inside the source organs at $6 \mathrm{~h}$ after injection (example in Figure 2). The fraction of injected activities (FIAs) were determined at each time point using the geometric mean counts from the planar images and the activity from the SPECT images.

The time-activity-curves were fitted with a mono- or bi-exponential function using the LevenbergMarquardt-based algorithm and were generated for every source organ (University of Szeged investigators). Absorbed doses for the target organs were estimated based on the RAdiation Dose Assessment Resource (RADAR, www.doseinfo-radar.com) scheme using the equation $D_{T}=\sum_{S} N_{S} \times D F(D \leftarrow S)$ where $\mathrm{D}_{\mathrm{T}}$ is the dose of a given target organ, $\mathrm{N}_{\mathrm{S}}$ is the number of disintegrations that occur in a source organ, and DF is 
the dose factor, which gives the absorbed dose in a target per disintegration in a source (5). Integration of the time-activity curve was calculated for every source organ. Patient-specific volumes were used for the liver, kidneys, small intestines, spleen, salivary glands and body remainder mass determination.

In a second step, the curve-fitting and dose calculations were performed using OLINDA/EXM® (Organ Level INternal Dose Assessment/EXponential Modeling) v.2.0 software (Hermes Medical Solutions), for comparison and method validation (UCLA investigators). For each volunteer, the non-decay-corrected percent injected activity in the source organs at each time point was used to generate time-activity curves. The same patient-specific volumes were used as in the manual method. Bi-exponential curve-fitting in OLINDA/EXM v.2.0 was used to fit the time-activity curves. The individual volunteer dose reports were compiled as means $\pm \mathrm{SD}$. Effective dose calculations were done using tissue weighting factors according to recommendations of the International Commission on Radiological Protection (6).

\section{Biodistribution in PCa Patients}

The PROMISE miTNM scoring system was used to report the scan findings (7). Tumor, bladder, and intestine volumetric contours were manually delineated on the SPECT/CT images $(+6 \mathrm{~h})$ by two experienced nuclear medicine physicians (ZsB and LP). A background VOI with the same size as the tumor VOI was placed on gluteal muscles to quantify muscle background uptake. Using patient weight, injected activity and Tc-99m camera calibration factor the SUV were calculated as follow: SUVmean $(\mathrm{g} / \mathrm{ml})=($ Total radioactivity/Volume of VOI) / (Injected radioactivity/Body weight) and SUVmax ( $\mathrm{g} / \mathrm{ml})=($ Maximum radioactivity/Volume of VOI) / (Injected radioactivity/Body weight). TBRs were calculated as follows: Tumor/Muscle (T/M, Tumor SUVmax / Muscle SUVmean), Tumor/Bladder (T/B, Tumor SUVmax / Bladder SUVmean) and Tumor/Intestine (T/I, Tumor SUVmax / Intestine SUVmean) ratios. 


\section{Statistics}

Descriptive statistics were used (median, mean, range). Wilcoxon signed-rank test was used to compare the doses obtained with the 2 methods.

\section{RESULTS}

\section{Patients}

Patients were enrolled from 12.14.2017 to 11.14 .2018 . In the dosimetry cohort of healthy volunteer men $(\mathrm{n}=4)$ the median age was 66 (range 57-70) and the median weight was 88kgs (range 83-95) (details are in Table 1). In the biodistribution cohort of patients with newly diagnosed $\mathrm{PCa}(\mathrm{n}=10)$ the median age was 67 (range 63-74), median weight $88 \mathrm{kgs}$ (range 54-130) (details are in Table 1). The median PSA was $10.1 \mathrm{ng} / \mathrm{ml}$ (range $0.34-44.3$ ). The number of patients of with PCa disease Gleason score of 6,7,8,9, 10 was $1(10 \%), 5(50 \%), 1(10 \%), 1(10 \%)$ and $2(20 \%)$, respectively.

\section{Radiation Dosimetry in Healthy Volunteers}

The median injected activity of Tc-99m PSMA I\&S was 739 MBq (range 562-828). No adverse events related to the injection of Tc-99m-PSMA-I\&S were reported. Tc-99m PSMA I\&S uptake was observed mainly in the salivary glands, liver, kidneys, spleen, small intestine, large intestine and urinary bladder. Figure 3 depicts an example of time-activity curves of normal organs in a healthy volunteer (patient \#003). Absorbed and effective doses using the manual RADAR and OLINDA/EXM method are presented in Table 2. Detailed fitting parameters are presented in Supplemental Table 1.

Using OLINDA/EXM® method, the mean absorbed dose (mGy/MBq) was the highest in the kidneys (0.0733 $\mathrm{mGy} / \mathrm{MBq})$ followed by the salivary glands $(0.0221 \mathrm{mGy} / \mathrm{MBq})$, the adrenals $(0.0217 \mathrm{mGy} / \mathrm{MBq})$, the liver $(0.0123 \mathrm{mGy} / \mathrm{MBq})$, the spleen $(0.0119 \mathrm{mGy} / \mathrm{MBq})$ and the small intestine $(0.0119 \mathrm{mGy} / \mathrm{MBq}$. Total body effective doses of the four volunteers were: 0.0053 (\#001), 0.0048 (\#002), 0.0051 (\#003) and 0.0055 (\#004) $\mathrm{mSv} / \mathrm{MBq}$. The average total body effective dose was $0.0052 \mathrm{mSv} / \mathrm{MBq}$. Considering the 
injected activities (range: 562-828 MBq), the effective doses of the four volunteers were between 3.11-4.23 $\mathrm{mSv}$.

Using manual RADAR method, the effective doses of the four volunteers were: 0.0052 (\#001), 0.0056 (\#002), 0.0053 (\#003), and 0.0059 (\#004) mSv/MBq, respectively, with an average effective dose of 0.0055 $\mathrm{mSv} / \mathrm{MBq}$. Considering the injected activities (range: 562-828 MBq), the effective doses of the four volunteers were between 3.33-4.42 mSv. Between methods, the dose values were very similar; the largest difference observed in mean effective dose was for the liver ( $9.5 \%$ difference), except gastrointestinal tract, which were defined differently in the two methods. There was no statistically significant difference between the paired mean effective doses $(\mathrm{mSv} / \mathrm{MBq})$ obtained by the two methods (paired Wilcoxon signed-rank test, $\mathrm{p}>0.05, \mathrm{LLI} / \mathrm{ULI}$ and left/right colon were excluded).

\section{Biodistribution Study in Patients with Prostate Cancer}

The median injected activity of Tc-99m PSMA I\&S was $695 \mathrm{MBq}$ (range 553-821). No adverse events related to the injection of Tc-99m-PSMA-I\&S were reported. High uptake of Tc-99m-PSMA I\&S was observed 6 hours after injection both in primary tumors (10/10 patients (100\%), mean SUVmax 13.37 (range 3.25-44.00), and in metastatic lesions (3/10 patients (30\%), mean SUVmax 5.71 (range 1.80-8.48) (Table 3). The mean T/M, T/B, T/I ratio in the primary tumors was 30.22 (range 7.95-110.00), 1.59 (range 0.11-7.02), 5.56 (range 0.96-16.30) and in the metastasis 14.97 (range 5.29-24.23) 0.60 (range 0.33-0.92), 3.16 (range 1.20-4.82), respectively. Figure 4 shows pathological tracer uptake in primary PCa (\#012), and in patients with metastases in bone (\#011) and lymph nodes (\#014). Based on the SPECT counts, the average activity of the pathological lesions 6 hours after tracer injection was $0.16 \mathrm{MBq}$ (range 0.01-0.96). Based on the physical half-life of Tc-99m, the average lesion activity after 24 and 48 hours was estimated to be $19.73 \mathrm{kBq}$ (range $1.25-120.00$ ) and $1.23 \mathrm{kBq}$ (range $0.08-7.55)$, respectively. 


\section{DISCUSSION}

Herein we report the radiation dose deposition of Tc-99m-PSMA I\&S in organs of 4 healthy volunteer patients with a hybrid imaging method (multiple sequential time-point planar imaging and one single SPECT/CT). Radiation dosimetry analysis is required for further clinical translation and approval by regulatory agencies. The average effective whole-body dose for administration of $700 \mathrm{MBq}$ Tc-99m-PSMA I\&S was $3.63 \pm 0.64 \mathrm{mSv}(\mathrm{OLINDA} / \mathrm{EXM})$. The mean effective dose of Tc-99m-PSMA I\&S $(0.0052$ $\mathrm{mSv} / \mathrm{MBq})$ is similar to conventional Tc-99m- MDP (8) used in SPECT/CT scans (0.004 mSv/MBq).

Several other Tc-99m-PSMA compounds have been developed; including among others TcEDDA/HYNIC-iPSMA (9), Tc-99m-tricarbonyl-iPSMA (10), Tc-99m-MIP-1404 and Tc-99m-MIP-1405 (11). In comparison with currently available Tc-labeled PSMA inhibitors, the effective dose of Tc-99mPSMA I\&S (0.0052 mSv/MBq) is similar to Tc-99m-EDDA/HYNIC-iPSMA (0.0046 mSv/MBq) and lower than Tc-99m-MIP-1404 (0.0088 mSv/MBq) and Tc-99m-MIP-1405 (0.0079 mSv/MBq) agents. The radiation absorbed doses of $740 \mathrm{MBq}$ Tc-99m PSMA I\&S in the liver (9.10 mSv) was lower than those of Tc-99m -EDDA/HYNIC-iPSMA (liver $=10.73 \mathrm{mSv})$, however small intestine $(8.83 \mathrm{mSv})$, spleen $(8.83$ $\mathrm{mSv})$, kidneys (54.24 $\mathrm{mSv})$ and salivary glands $(16.35 \mathrm{mSv})$ have higher dose than Tc-99m EDDA/HYNIC-iPSMA (small intestine $=2.42 \mathrm{mSv}$, spleen $=7.06 \mathrm{mSv}$, kidney $=28.80 \mathrm{mSv}$, salivary glands $=9.69 \mathrm{mSv}$ ) (9). In comparison to the PET tracers, the effective dose of Tc-99m-PSMA I\&S is lower than 68Ga-labelled (68Ga-PSMA-11 (0.0236 mSv/MBq, (12)) and 18F-labelled (0.0220 mSv/MBq, (13)) PSMA-targeted tracers.

The dose calculation and verification using OLINDA/EXM v2.0 software contained the same main steps. The largest difference was in the exponential curve-fitting method: OLINDA was used for bi-exponential curve fitting in every case, whereas the manual method used mono- or bi-exponential fitting, based on visual assessment. As shown in Figure 3, there were cases, when the mono-exponential fit was adequate (liver, spleen, remainder of body by visual inspection). Therefore, there were only minor differences in the calculated number of disintegrations of source organs between both methods. Another difference was the 
segments definition of the gastrointestinal tract: RADAR contained dose factors for ULI and LLI, whereas OLINDA/EXM calculates doses to the left and right colon.

Detailed biodistribution data for Tc-99m-PSMA I\&S has been published by Robu et al (2). Relatively high blood and background activity were observed due to high plasma protein binding of the radiopharmaceutical (94\%). Tc-99m PSMA I\&S is excreted primarily by the urinary system; although, increased lipophilicity of the tracer enhances liver uptake and higher consent rate of hepatobiliary clearance which led to increased intestinal activity. In our study, intestinal tracer accumulation was found to be highly variable as well as bladder activity.

Both SPECT/CT imaging systems and SPECT tracers are more affordable than PET/CT systems. Tc-99mPSMA I\&S can represent a valuable alternative to PSMA PET imaging in countries in development. Another potential application of Tc-99m-PSMA I\&S is RGS. PSMA-targeted RGS can help and guide urologists to detect PCa lymph node (LN) metastasis during surgery. PSMA-expressing LNs can be detected intraoperatively using a gamma probe. Despite the use of PSMA-targeted PET as a tool for preoperative guidance, intraoperative detection and resection of small lesions remains challenging, especially because of the small dimension of the LN metastasis, the technical difficulty of pelvic LN dissection, and atypical anatomic localization of the LNs. Farolfi et al. reported that in up to two-thirds of patients who experienced disease recurrence after surgery, at least one lesion had already been detected on the preoperative PSMA-targeted PET imaging, suggesting that LN dissection was often not complete (14). PSMA-targeted RGS might increase surgeon's confidence in intraoperative detection and complete dissection of metastatic LNs lesions detected in the preoperative PSMA-targeted SPECT and PET imaging. European retrospective studies conducted in large cohorts reported high rates of intraoperative tumor detection validated by histopathology, as well as improved treatment outcome $(3,4)$. Of note, a first European clinical trial is currently investigating the feasibility of PSMA-targeted RGS (TRACE: NCT03857113). 
The timing of tracer administration for RGS has been determined empirically and may be improved. In this cohort the activity in the target lesions of between 24-48 hours after injection remains in the detectable range for commercially available gamma probes. The minimum acceptable sensitivity of a gamma probe system sensitivity for clinical use is $2.5 \mathrm{cps} / \mathrm{kBq}(15)$. Therefore, the gamma probe could detect the tumors between 24-48h following tracer administration. Even though Tc-99m-PSMA I\&S showed good TBR in both primary and metastatic lesions, differentiation between pathological and physiological uptake can be difficult because of the urinary and intestinal tracer accumulation. Based on our TBRs, tumor differentiation from the intestine seems to be easier than from the bladder on the SPECT/CT at $+6 \mathrm{~h}$. However, after 24 hours, a lower activity is expected due to urinary and intestinal elimination in contrast with the stable tumor uptake.

\section{CONCLUSION}

This dosimetry study of Tc-99m-PSMA I\&S showed that injected activities of 562-828 MBq translate to estimated effective doses of 3.33-4.42 mSv (manual RADAR method) and 3.11-4.23 mSv (OLINDA/EXM method), which is similar to the effective doses from other Tc-99m PSMA inhibitors. Preliminary data suggest high TBR of primary and metastatic PCa lesions. Larger trials are needed to further define its capabilities in the management of prostate cancer.

\section{Disclosure}

No potential conflict of interest relevant to this article was reported.

\section{KEY POINTS}

QUESTION: What is the radiation dosimetry and biodistribution of Tc-99m-PSMA I\&S?

PERTINENT FINDINGS: Based on a hybrid method using serial planar gamma imaging and one SPECT/CT scans acquired in 4 healthy volunteers, the average effective whole-body dose estimation for 
administration of $700 \mathrm{MBq}$ Tc-99m PSMA I\&S was $3.64 \mathrm{mSv}$ which is comparable to other technetium$99 \mathrm{~m}$ based tracers.

IMPLICATIONS FOR PATIENT CARE: This study provides required data for translation and approval of Tc-99m-PSMA I\&S by regulatory agencies 


\section{REFERENCES}

[1] Rajasekaran AK, Anilkumar G, Christiansen JJ. Is prostate-specific membrane antigen a multifunctional protein?. Am J Physiol Cell Physiol. 2005;288:C975-C981.

[2] Robu S, Schottelius M, Eiber M, et al. Preclinical evaluation and first patient application of 99mTcPSMA-I\&S for SPECT imaging and radioguided surgery in prostate cancer. J Nucl Med. 2017;58:235-242.

[3] Horn T, Krönke M, Rauscher I, et al. Single lesion on prostate-specific membrane antigen-ligand Positron Emission Tomography and low prostate-specific antigen are prognostic factors for a favorable biochemical response to prostate-specific membrane antigen-targeted radioguided surgery in recurrent prostate cancer. Eur Urol. 2019;76:517-523.

[4] Maurer T, Robu S, Schottelius M, et al. 99mTechnetium-based prostate-specific membrane antigenradioguided surgery in recurrent prostate cancer. Eur Urol. 2019;75:659-666.

[5] Stabin MG, Sparks RB, Crowe E. OLINDA/EXM: the second-generation personal computer software for internal dose assessment in nuclear medicine. J Nucl Med. 2005;46:1023-1027.

[6 The 2007 Recommendations of the International Commission on Radiological Protection. ICRP publication 103. Ann ICRP. 2007;37:1-332.

[7] Eiber M, Herrmann K, Calais J, et al. Prostate Cancer Molecular Imaging Standardized Evaluation (PROMISE): Proposed miTNM classification for the interpretation of PSMA-ligand PET/CT [published correction appears in J Nucl Med. 2018 Jun;59(6):992]. J Nucl Med. 2018;59:469-478.

[8] Ferrari M, De Marco P, Origgi D, et al. SPECT/CT radiation dosimetry. Clin Transl Imaging 2014;2:557-569.

[9] Santos-Cuevas C, Davanzo J, Ferro-Flores G, et al. 99mTc-labeled PSMA inhibitor: Biokinetics and radiation dosimetry in healthy subjects and imaging of prostate cancer tumors in patients. Nucl Med Biol. $2017 ; 52: 1-6$

[10] Hillier SM, Maresca KP, Lu G, et al. 99mTc-labeled small-molecule inhibitors of prostate-specific membrane antigen for molecular imaging of prostate cancer. $J$ Nucl Med. 2013;54:1369-1376. 
[11] Vallabhajosula S, Nikolopoulou A, Babich JW, et al. 99mTc-labeled small-molecule inhibitors of prostate-specific membrane antigen: pharmacokinetics and biodistribution studies in healthy subjects and patients with metastatic prostate cancer. $J$ Nucl Med. 2014;55:1791-1798.

[12] Afshar-Oromieh A, Hetzheim H, Kübler W, et al. Radiation dosimetry of (68)Ga-PSMA-11 (HBEDCC) and preliminary evaluation of optimal imaging timing. Eur J Nucl Med Mol Imaging. 2016;43:16111620.

[13] Giesel FL, Hadaschik B, Cardinale J, et al. F-18 labelled PSMA-1007: biodistribution, radiation dosimetry and histopathological validation of tumor lesions in prostate cancer patients. Eur J Nucl Med Mol Imaging. 2017;44:678-688.

[14] Farolfi A, Gafita A, Calais J, et al. 68Ga-PSMA-11 Positron Emission Tomography detects residual prostate cancer after prostatectomy in a multicenter retrospective study. J Urol. 2019;202:1174-1181.

[15] Matheoud R, Giorgione R, Valzano S, Sacchetti G, Colombo E, Brambilla M. Minimum acceptable sensitivity of intraoperative gamma probes used for sentinel lymph node detection in melanoma patients. Phys Med. 2014;30:822-826. 
Figures:

Figure 1. Example of source organs and background ROIs in a healthy volunteer (patient \#003) on planar scintigraphy images (A); WB anterior and posterior Tc-99m-Mas3-y-nal-k(Sub-KuE) scintigraphy was performed at 1, 2, 3, 6 and $24 \mathrm{~h}$ p. i. (A-E)

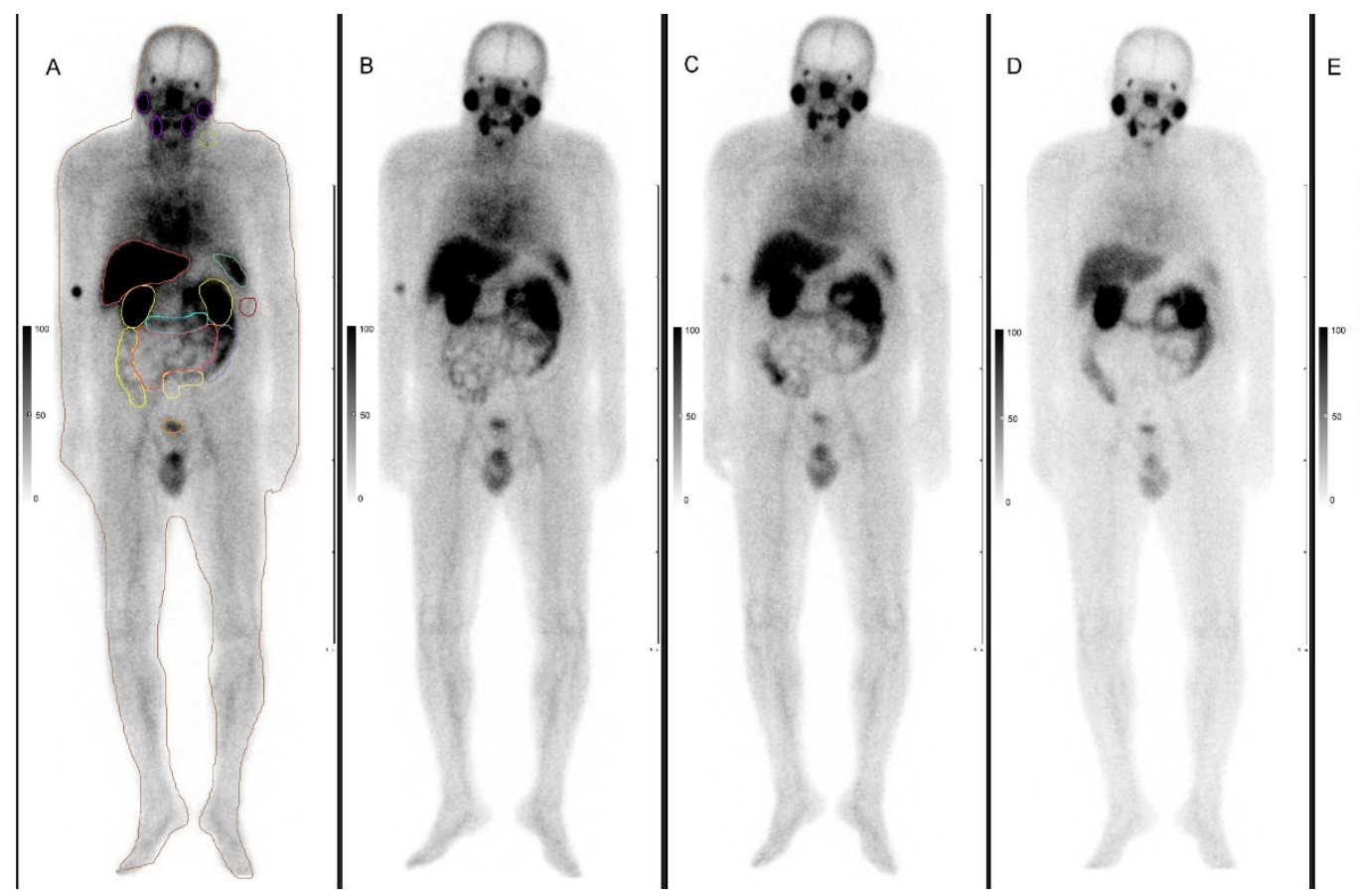


Figure 2. Example of organ delineation in healthy/PCa patient (\#003) on SPECT/CT images. (A); Tc-99m PSMA I\&S SPECT 3D MIP (B)
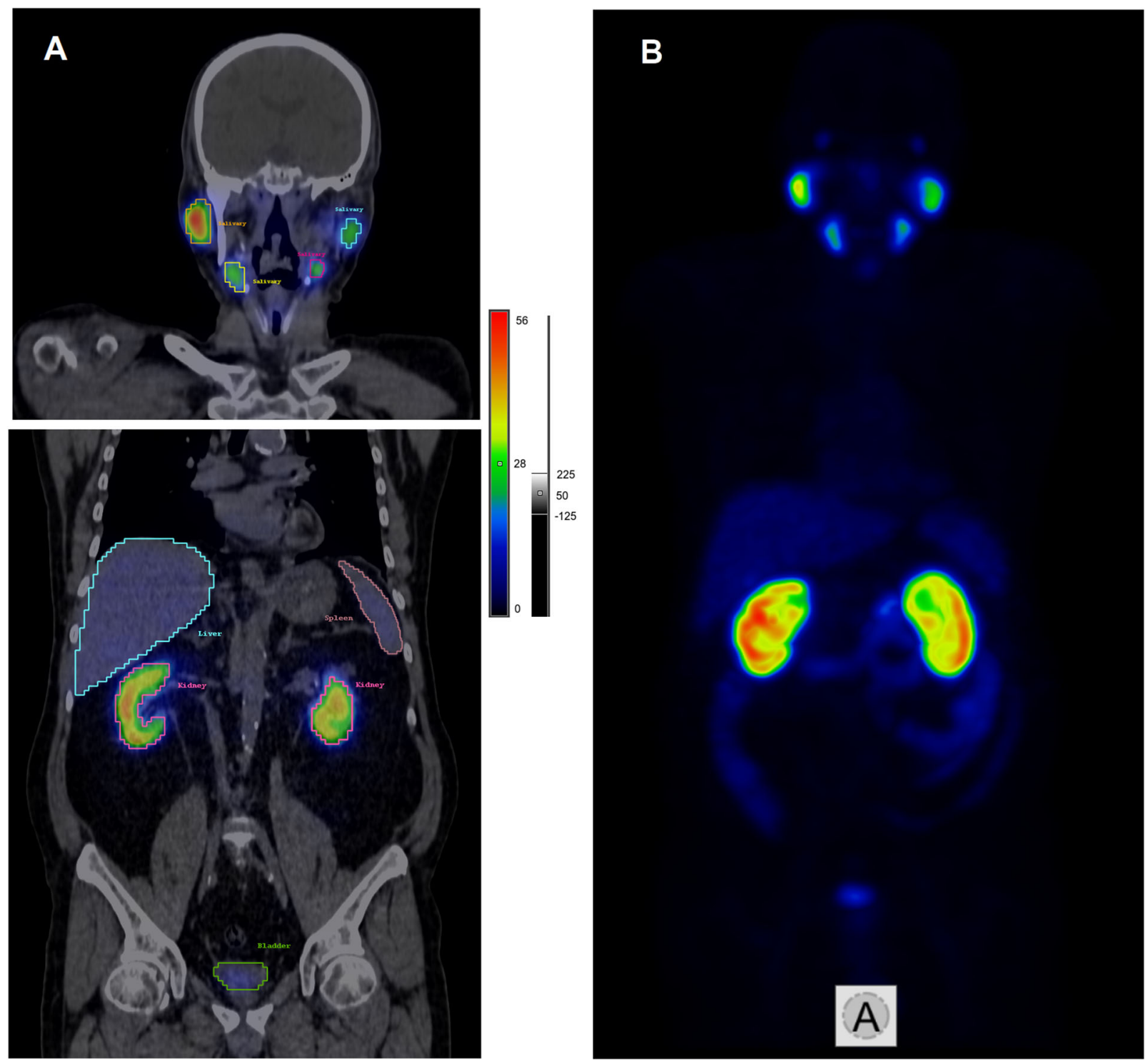
Figure 3. Example of time-activity-curves of normal organs in a healthy volunteer (patient \#003)
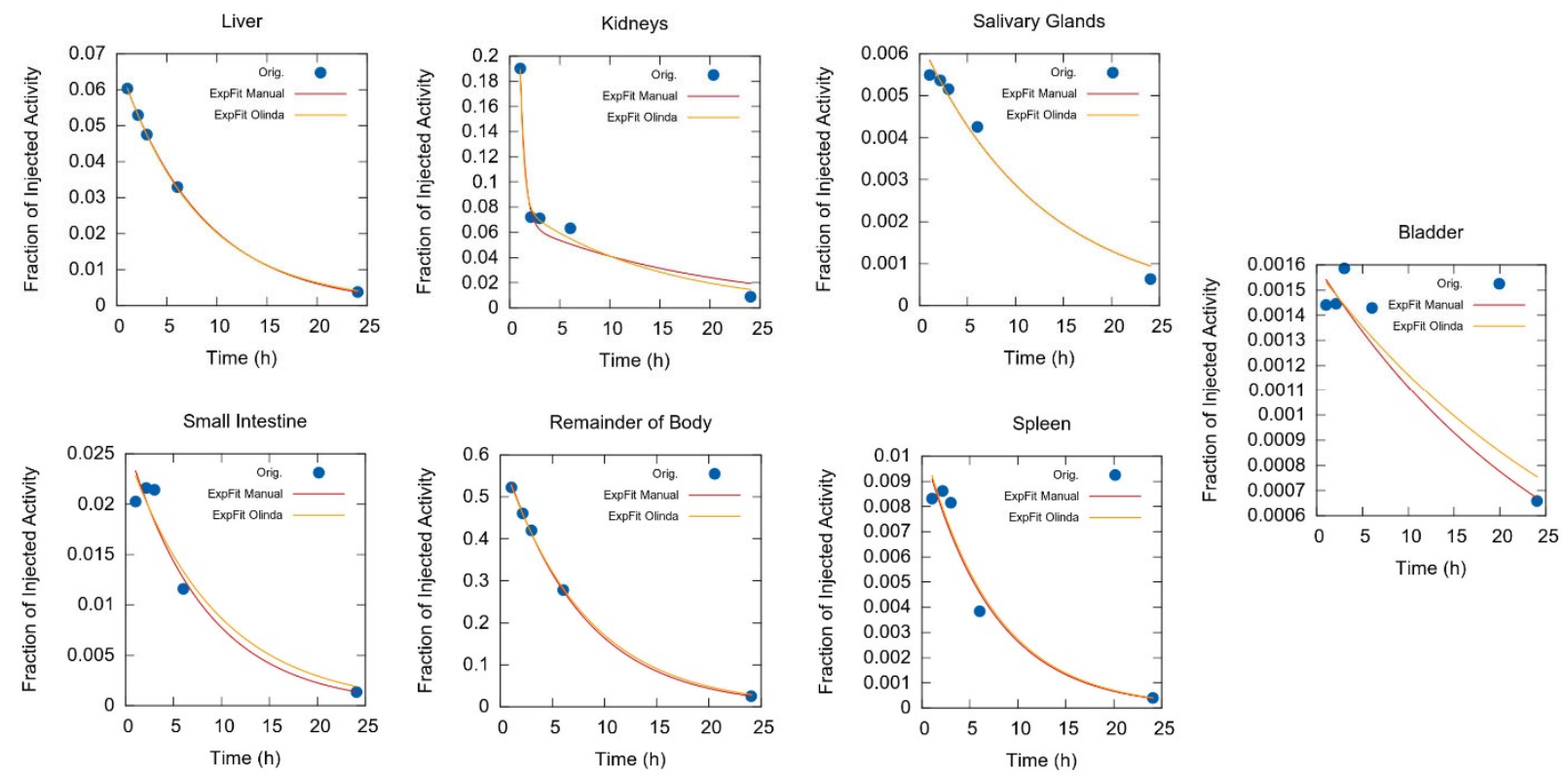
Figure 4. Low-dose CT (A), Tc-99m-PSMA-SPECT/CT (B) of a PCa primary tumor lesion (patient \#012) with high TBR (SUVmax 22.00 TBR 42.30); Low-dose CT (C), Tc-99m-PSMASPECT /CT (D) of a PCa bone metastasis (patient \#011) with high TBR (SUVmax 11.89 TBR 25.85); Low-dose CT (E), Tc-99m-PSMA-SPECT/CT (F) of PCa lymph node metastases (patient \#014) with high TBR (SUVmax 8.23 TBR 23.51 and SUVmax 8.48 TBR 24.23).
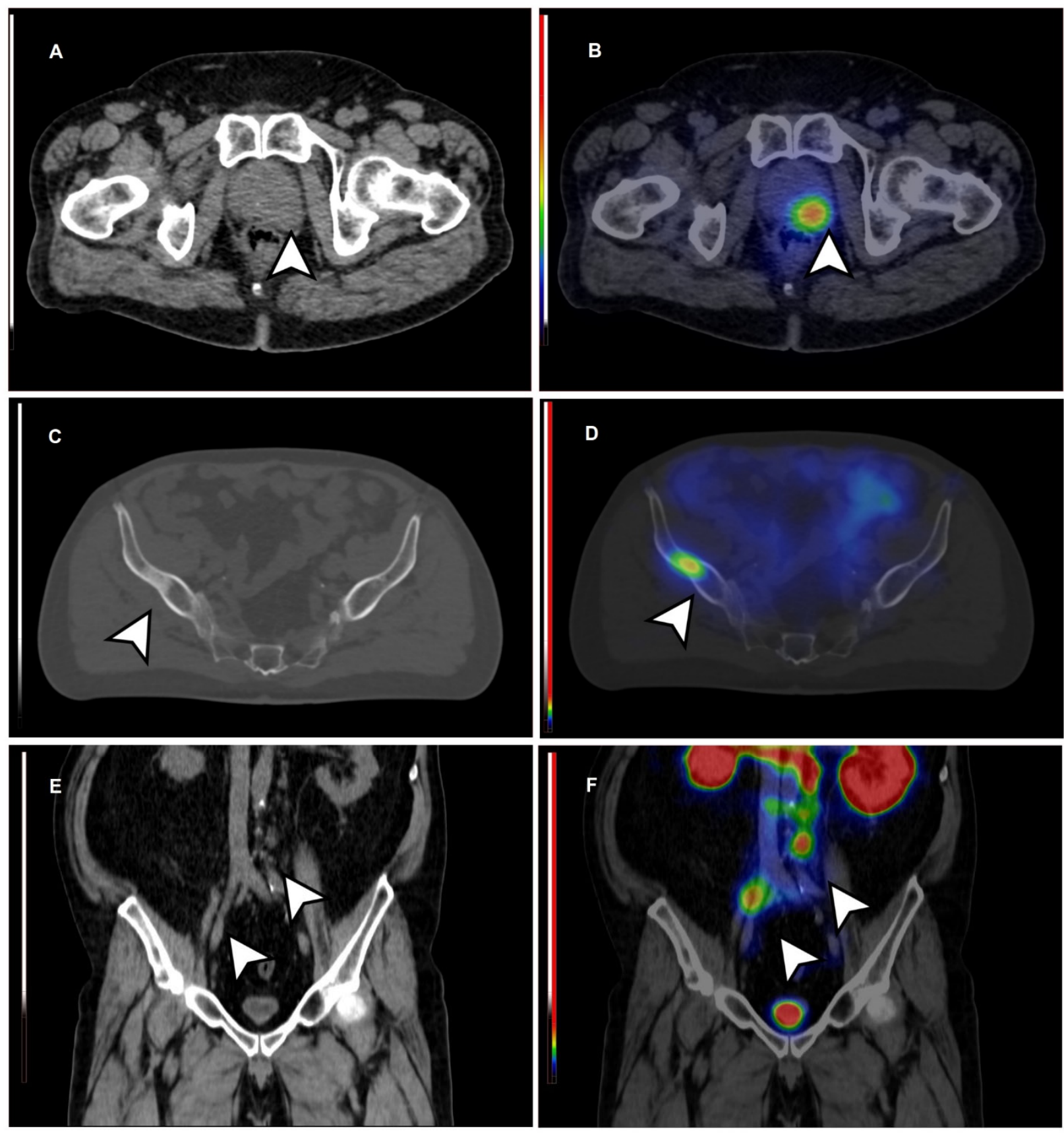
Table 1: Patients characteristics

\begin{tabular}{|c|c|c|c|c|c|c|}
\hline $\begin{array}{l}\text { Patient } \\
\text { No. }\end{array}$ & Age (y) & $\begin{array}{c}\text { Weight } \\
(\mathrm{kg})\end{array}$ & Indication & $\begin{array}{c}\text { PSA } \\
(\mathrm{ng} / \mathrm{ml})\end{array}$ & $\begin{array}{c}\text { Gleason } \\
\text { Score }\end{array}$ & $\begin{array}{c}\text { Inj. } \\
\text { Activity } \\
(\mathrm{MBq})\end{array}$ \\
\hline$\# 001$ & 57 & 95 & Healthy Volunteer & NA & NA & 674 \\
\hline \#002 & 68 & 92 & Healthy Volunteer & NA & NA & 804 \\
\hline$\# 003$ & 64 & 83 & Healthy Volunteer & NA & NA & 828 \\
\hline$\# 004$ & 70 & 84 & Healthy Volunteer & NA & NA & 562 \\
\hline$\# 005$ & 64 & 81 & Initial staging of $\mathrm{PCa}$ & 8.84 & 6 & 634 \\
\hline \#006 & 66 & 110 & Initial staging of $\mathrm{PCa}$ & 11.37 & 7 & 553 \\
\hline$\# 007$ & 67 & 86 & Initial staging of $\mathrm{PCa}$ & 1.02 & 10 & 682 \\
\hline$\# 008$ & 73 & 120 & Initial staging of $\mathrm{PCa}$ & 0.34 & 7 & 748 \\
\hline$\# 009$ & 63 & 130 & Initial staging of $\mathrm{PCa}$ & 21.2 & 7 & 698 \\
\hline$\# 010$ & 70 & 85 & Initial staging of $\mathrm{PCa}$ & 18.46 & 8 & 692 \\
\hline \#011 & 66 & 78 & Initial staging of $\mathrm{PCa}$ & 4.23 & 9 & 780 \\
\hline$\# 012$ & 74 & 90 & Initial staging of $\mathrm{PCa}$ & 4.21 & 7 & 821 \\
\hline \#013 & 71 & 54 & Initial staging of $\mathrm{PCa}$ & 44.3 & 7 & 714 \\
\hline$\# 014$ & 64 & 110 & Initial staging of $\mathrm{PCa}$ & 18.2 & 10 & 624 \\
\hline
\end{tabular}


Table 2. Organ absorbed and effective doses of Tc-99m-Mas3-y-nal-k(Sub-KuE) using manual RADAR and OLINDA/EXM 2.0 methods

\begin{tabular}{|c|c|c|c|c|c|c|}
\hline \multirow{3}{*}{ Target Organ } & \multicolumn{3}{|c|}{ Manual RADAR } & \multicolumn{3}{|c|}{ OLINDA/EXM } \\
\hline & \multicolumn{2}{|c|}{$\begin{array}{l}\text { Organ doses } \\
\text { (mGy/MBq) }\end{array}$} & \multirow{2}{*}{$\begin{array}{c}\text { Effective Doses } \\
\text { (mSv/MBq) }\end{array}$} & \multicolumn{2}{|c|}{$\begin{array}{l}\text { Organ doses } \\
(\mathrm{mGy} / \mathrm{MBq})\end{array}$} & \multirow{2}{*}{\begin{tabular}{|c|}
$\begin{array}{c}\text { Effective Doses } \\
\text { (mSv/MBq) }\end{array}$ \\
Mean
\end{tabular}} \\
\hline & Mean & Std & & Mean & Std & \\
\hline Adrenals & $2.17 \mathrm{E}-02$ & $4.54 \mathrm{E}-03$ & $2.00 \mathrm{E}-04$ & $2.17 \mathrm{E}-02$ & $5.62 \mathrm{E}-03$ & $2.00 \mathrm{E}-04$ \\
\hline Brain & $2.13 \mathrm{E}-03$ & $1.59 \mathrm{E}-04$ & $2.13 \mathrm{E}-05$ & $2.15 \mathrm{E}-03$ & $2.20 \mathrm{E}-04$ & $2.15 \mathrm{E}-05$ \\
\hline Esophagus & $4.08 \mathrm{E}-03$ & $2.60 \mathrm{E}-04$ & $1.63 \mathrm{E}-04$ & $3.98 \mathrm{E}-03$ & $3.12 \mathrm{E}-04$ & $1.59 \mathrm{E}-04$ \\
\hline Eyes & $2.02 \mathrm{E}-03$ & $1.69 \mathrm{E}-04$ & $0.00 \mathrm{E}-00$ & $2.04 \mathrm{E}-03$ & $2.23 \mathrm{E}-04$ & $0.00 \mathrm{E}+00$ \\
\hline Gallbladder Wall & $8.98 \mathrm{E}-03$ & $6.34 \mathrm{E}-04$ & $8.30 \mathrm{E}-05$ & $8.22 \mathrm{E}-03$ & $5.89 \mathrm{E}-04$ & $7.59 \mathrm{E}-05$ \\
\hline LLI/Left Colon & $1.02 \mathrm{E}-02$ & $1.74 \mathrm{E}-03$ & $4.94 \mathrm{E}-04$ & $8.90 \mathrm{E}-03$ & $7.57 \mathrm{E}-04$ & $4.31 \mathrm{E}-04$ \\
\hline Small Intestine & $1.15 \mathrm{E}-02$ & $3.93 \mathrm{E}-03$ & $1.07 \mathrm{E}-04$ & $1.19 \mathrm{E}-02$ & $3.82 \mathrm{E}-03$ & $1.10 \mathrm{E}-04$ \\
\hline Stomach Wall & $5.11 \mathrm{E}-03$ & $2.84 \mathrm{E}-04$ & $6.13 \mathrm{E}-04$ & $5.00 \mathrm{E}-03$ & $4.03 \mathrm{E}-04$ & $6.00 \mathrm{E}-04$ \\
\hline ULI/Right Colon & $1.12 \mathrm{E}-02$ & $2.66 \mathrm{E}-03$ & $5.43 \mathrm{E}-04$ & $8.49 \mathrm{E}-03$ & $1.03 \mathrm{E}-03$ & $4.12 \mathrm{E}-04$ \\
\hline Rectum & $4.56 \mathrm{E}-03$ & $7.54 \mathrm{E}-04$ & $1.05 \mathrm{E}-04$ & $4.45 \mathrm{E}-03$ & $4.74 \mathrm{E}-04$ & $1.02 \mathrm{E}-04$ \\
\hline Heart Wall & $4.12 \mathrm{E}-03$ & $2.65 \mathrm{E}-04$ & $3.80 \mathrm{E}-05$ & $4.00 \mathrm{E}-03$ & $3.01 \mathrm{E}-04$ & $3.69 \mathrm{E}-05$ \\
\hline Kidneys & $7.20 \mathrm{E}-02$ & $2.34 \mathrm{E}-02$ & $6.64 \mathrm{E}-04$ & $7.33 \mathrm{E}-02$ & $2.66 \mathrm{E}-02$ & $6.77 \mathrm{E}-04$ \\
\hline Liver & $1.35 \mathrm{E}-02$ & $1.92 \mathrm{E}-03$ & $5.43 \mathrm{E}-04$ & $1.23 \mathrm{E}-02$ & $1.76 \mathrm{E}-03$ & $4.93 \mathrm{E}-04$ \\
\hline Lungs & $3.46 \mathrm{E}-03$ & $2.36 \mathrm{E}-04$ & $4.15 \mathrm{E}-04$ & $3.37 \mathrm{E}-03$ & $2.82 \mathrm{E}-04$ & $4.05 \mathrm{E}-04$ \\
\hline Pancreas & $7.59 \mathrm{E}-03$ & $4.58 \mathrm{E}-04$ & $7.01 \mathrm{E}-05$ & $7.23 \mathrm{E}-03$ & $2.77 \mathrm{E}-04$ & $6.67 \mathrm{E}-05$ \\
\hline Prostate & $4.60 \mathrm{E}-03$ & $6.36 \mathrm{E}-04$ & $2.12 \mathrm{E}-05$ & $4.50 \mathrm{E}-03$ & $3.74 \mathrm{E}-04$ & $2.08 \mathrm{E}-05$ \\
\hline Salivary Glands & $2.32 \mathrm{E}-02$ & $3.05 \mathrm{E}-03$ & $2.32 \mathrm{E}-04$ & $2.21 \mathrm{E}-02$ & $3.02 \mathrm{E}-03$ & $2.21 \mathrm{E}-04$ \\
\hline Red Marrow & $3.43 \mathrm{E}-03$ & $1.79 \mathrm{E}-04$ & $4.12 \mathrm{E}-04$ & $3.41 \mathrm{E}-03$ & $2.56 \mathrm{E}-04$ & 4.10E-04 \\
\hline Osteogenic Cells & $6.39 \mathrm{E}-03$ & $3.80 \mathrm{E}-04$ & $6.39 \mathrm{E}-05$ & $6.45 \mathrm{E}-03$ & $5.03 \mathrm{E}-04$ & $6.45 \mathrm{E}-05$ \\
\hline Spleen & $1.23 \mathrm{E}-02$ & $3.31 \mathrm{E}-03$ & $1.14 \mathrm{E}-04$ & $1.19 \mathrm{E}-02$ & $3.07 \mathrm{E}-03$ & $1.10 \mathrm{E}-04$ \\
\hline Testes & $2.24 \mathrm{E}-03$ & $1.66 \mathrm{E}-04$ & $8.94 \mathrm{E}-05$ & $2.25 \mathrm{E}-03$ & $1.97 \mathrm{E}-04$ & $9.00 \mathrm{E}-05$ \\
\hline Thymus & $2.79 \mathrm{E}-03$ & $2.21 \mathrm{E}-04$ & $2.58 \mathrm{E}-05$ & $2.78 \mathrm{E}-03$ & $2.77 \mathrm{E}-04$ & $2.57 \mathrm{E}-05$ \\
\hline Thyroid & $2.59 \mathrm{E}-03$ & $2.11 \mathrm{E}-04$ & $1.03 \mathrm{E}-04$ & $2.62 \mathrm{E}-03$ & $2.68 \mathrm{E}-04$ & $1.05 \mathrm{E}-04$ \\
\hline $\begin{array}{c}\text { Urinary Bladder } \\
\text { Wall }\end{array}$ & $9.54 \mathrm{E}-03$ & $6.18 \mathrm{E}-03$ & $3.81 \mathrm{E}-04$ & 8.89E-03 & $4.92 \mathrm{E}-03$ & $3.55 \mathrm{E}-04$ \\
\hline Total Body & $3.03 \mathrm{E}-03$ & $2.54 \mathrm{E}-04$ & $0.00 \mathrm{E}-00$ & $3.15 \mathrm{E}-03$ & $3.08 \mathrm{E}-04$ & $0.00 \mathrm{E}+00$ \\
\hline
\end{tabular}


Table 3: Biodistribution study of Tc-99m-PSMA I\&S in patients with PCa

T/M: tumor to muscle background ratio; T/B: tumor to bladder background ratio; T/I: tumor to intestine background ratio

\begin{tabular}{|c|c|c|c|c|c|c|c|c|c|c|c|}
\hline \multirow{2}{*}{$\begin{array}{l}\text { Patient } \\
\text { No. }\end{array}$} & \multirow{2}{*}{$\begin{array}{c}\text { Gleason } \\
\text { Score }\end{array}$} & \multirow{2}{*}{$\begin{array}{c}\text { PSA } \\
(\mathrm{ng} / \mathrm{ml})\end{array}$} & \multirow{2}{*}{ PROMISE MiTNM } & \multicolumn{2}{|c|}{ Tumor SUVmax } & \multicolumn{2}{|r|}{$\mathrm{T} / \mathrm{M}$ ratio } & \multicolumn{2}{|r|}{$\mathrm{T} / \mathrm{B}$ ratio } & \multicolumn{2}{|r|}{$\mathrm{T} / \mathrm{I}$ ratio } \\
\hline & & & & $\mathrm{PCa}$ & Metastasis & $\mathrm{PCa}$ & Metastasis & $\mathrm{PCa}$ & Metastasis & $\mathrm{PCa}$ & Metastasis \\
\hline$\# 005$ & 6 & 8.84 & miT2uN0M0 & 10.95 & & 19.55 & & 0.12 & & 1.25 & \\
\hline$\# 006$ & 7 & 11.37 & miT2mN0M0 & 5.09 & & 7.95 & & 0.28 & & 2.81 & \\
\hline$\# 007$ & 10 & 1.02 & miT2uN0M0 & 8.1 & & 11.57 & & 0.94 & & 1.6 & \\
\hline$\# 008$ & 7 & 0.34 & miT2uN0M0 & 5.18 & & 8.09 & & 0.14 & & 2.3 & \\
\hline$\# 009$ & 7 & 21.2 & miT2uN0M0 & 44 & & 110 & & 7.02 & & 16.3 & \\
\hline$\# 010$ & 8 & 18.46 & miT3bN0M1b(oligo) & 16 & 1.8 & 47.06 & 5.29 & 4.15 & 0.47 & 10.67 & 1.20 \\
\hline$\# 011$ & 9 & 4.23 & miT2uN0M1b(oligo) & 11.89 & $4.25 ; 7.67$ & 25.85 & $9.24 ; 16.67$ & 0.92 & $0.33 ; 0.60$ & 6.1 & $2.18 ; 3.93$ \\
\hline$\# 012$ & 7 & 4.21 & miT2uN0M0 & 22 & & 42.3 & & 1.42 & & 9.44 & \\
\hline$\# 013$ & 7 & 44.3 & miT2uN0M0 & 3.25 & & 9.03 & & 0.11 & & 0.96 & \\
\hline \#014 & 10 & 18.2 & miT4N2b(RP,CIR,OBR)M0 & 7.29 & $3.82 ; 8.23 ; 8.48$ & 20.83 & $10.91 ; 23.51 ; 24.23$ & 0.79 & $0.42 ; 0.89 ; 0.92$ & 4.14 & $2.17 ; 4.68 ; 4.82$ \\
\hline
\end{tabular}


Supplemental Table 1. Fitting parameters of the mono- or biexponential curves $\left(y=A_{1} e^{-A 2} x+\right.$ $\mathrm{B}_{1} \mathrm{e}^{-\mathrm{B} 2} \mathrm{x}$ ) for estimating number of disintegration (Area Under Curve) inside source organs

\begin{tabular}{|c|c|c|c|c|c|c|c|c|c|c|c|}
\hline & & \multicolumn{4}{|c|}{ Manual curve-fitting } & & \multicolumn{4}{|c|}{ OLINDA/EXM curve-fitting } & \multirow[b]{2}{*}{ AUC [MBq-h/MBq] } \\
\hline & & A1 [FIA] & B1 [FIA] & A2 $\left[h^{-1}\right]$ & B2 $\left[\mathbf{h}^{-1}\right]$ & AUC [MBq-h/MBq] & A1 [FIA] & B1 [FIA] & A2 $\left[h^{-1}\right]$ & $\mathbf{B} 2\left[\mathrm{~h}^{-1}\right]$ & \\
\hline \multirow{9}{*}{ 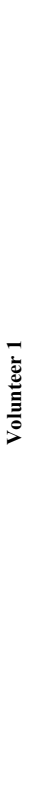 } & Liver & $7.21 \mathrm{E}-02$ & N.A. & $1.38 \mathrm{E}-01$ & N.A. & $5.21 \mathrm{E}-01$ & $6.41 \mathrm{E}-02$ & $1.41 \mathrm{E}-02$ & $1.96 \mathrm{E}-01$ & $\begin{array}{l}7.20 \mathrm{E}- \\
02\end{array}$ & $5.23 \mathrm{E}-01$ \\
\hline & Kidney & $1.00 \mathrm{E}+00$ & $7.00 \mathrm{E}-02$ & $1.49 \mathrm{E}+00$ & $\begin{array}{l}3.95 \mathrm{E}- \\
02\end{array}$ & $2.44 \mathrm{E}+00$ & $3.89 \mathrm{E}+00$ & $1.19 \mathrm{E}-01$ & $3.06 \mathrm{E}+00$ & $\begin{array}{c}8.05 \mathrm{E}- \\
02\end{array}$ & $2.75 \mathrm{E}+00$ \\
\hline & Small Intestine & $3.00 \mathrm{E}-02$ & N.A. & $1.28 \mathrm{E}-01$ & N.A. & $2.35 \mathrm{E}-01$ & $1.48 \mathrm{E}-02$ & $1.63 \mathrm{E}-02$ & $1.90 \mathrm{E}-01$ & $\begin{array}{c}1.02 \mathrm{E}- \\
01\end{array}$ & $2.38 \mathrm{E}-01$ \\
\hline & Spleen & $5.05 \mathrm{E}-03$ & N.A. & $1.50 \mathrm{E}-01$ & N.A. & 3.37E-02 & 1.06E-02 & $5.37 \mathrm{E}-03$ & $3.16 \mathrm{E}+00$ & $\begin{array}{c}1.81 \mathrm{E}- \\
01\end{array}$ & $3.30 \mathrm{E}-02$ \\
\hline & Salivary glands & $5.00 \mathrm{E}-01$ & $1.02 \mathrm{E}-02$ & $1.83 \mathrm{E}+02$ & $\begin{array}{l}7.87 \mathrm{E}- \\
02\end{array}$ & $1.33 \mathrm{E}-01$ & $5.23 \mathrm{E}-04$ & $1.02 \mathrm{E}-02$ & $1.60 \mathrm{E}+01$ & $\begin{array}{c}7.86 \mathrm{E}- \\
02\end{array}$ & $1.30 \mathrm{E}-01$ \\
\hline & Urinary bladder & $5.00 \mathrm{E}-01$ & $5.99 \mathrm{E}-03$ & $2.76 \mathrm{E}+02$ & $\begin{array}{c}7.84 \mathrm{E}- \\
02\end{array}$ & $7.82 \mathrm{E}-02$ & $7.88 \mathrm{E}-04$ & $5.98 \mathrm{E}-03$ & $1.37 \mathrm{E}+01$ & $\begin{array}{c}7.57 \mathrm{E}- \\
02\end{array}$ & $7.91 \mathrm{E}-02$ \\
\hline & Left Colon/LLI & $8.39 \mathrm{E}-04$ & N.A. & $1.05 \mathrm{E}-01$ & N.A. & $8.01 \mathrm{E}-03$ & $5.85 \mathrm{E}-04$ & $1.50 \mathrm{E}-03$ & $8.81 \mathrm{E}-02$ & $\begin{array}{c}8.81 \mathrm{E}- \\
02\end{array}$ & $2.37 \mathrm{E}-02$ \\
\hline & Right Colon/ULI & $5.00 \mathrm{E}-01$ & $9.00 \mathrm{E}-03$ & $2.98 \mathrm{E}+02$ & $\begin{array}{c}2.16 \mathrm{E}- \\
01\end{array}$ & $4.33 \mathrm{E}-02$ & $3.77 \mathrm{E}-03$ & 4.31E-03 & $5.72 \mathrm{E}-02$ & $\begin{array}{l}5.72 \mathrm{E}- \\
02\end{array}$ & $1.41 \mathrm{E}-01$ \\
\hline & $\begin{array}{l}\text { Remainder of } \\
\text { body }\end{array}$ & $5.48 \mathrm{E}-01$ & N.A. & $1.41 \mathrm{E}-01$ & N.A. & $3.89 \mathrm{E}+00$ & $5.40 \mathrm{E}-01$ & $4.80 \mathrm{E}-07$ & $1.35 \mathrm{E}-01$ & $\begin{array}{c}5.03 \mathrm{E}- \\
02\end{array}$ & $4.00 \mathrm{E}+00$ \\
\hline \multirow{9}{*}{ 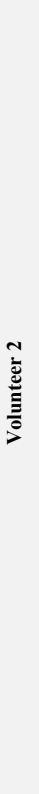 } & Liver & $9.61 \mathrm{E}-02$ & N.A. & $1.45 \mathrm{E}-01$ & N.A. & $6.64 \mathrm{E}-01$ & $8.37 \mathrm{E}-02$ & $1.25 \mathrm{E}-02$ & $1.48 \mathrm{E}-01$ & $\begin{array}{c}1.25 \mathrm{E}- \\
01\end{array}$ & $6.66 \mathrm{E}-01$ \\
\hline & Kidney & 4.60E-01 & $9.30 \mathrm{E}-02$ & $1.60 \mathrm{E}+02$ & $\begin{array}{l}8.73 \mathrm{E}- \\
02\end{array}$ & $1.07 \mathrm{E}+00$ & 7.46E-02 & $1.83 \mathrm{E}-02$ & $8.70 \mathrm{E}-02$ & $\begin{array}{c}8.71 \mathrm{E}- \\
02\end{array}$ & $1.07 \mathrm{E}+00$ \\
\hline & Small Intestine & $1.00 \mathrm{E}+00$ & $6.22 \mathrm{E}-02$ & $3.48 \mathrm{E}+00$ & $\begin{array}{c}1.01 \mathrm{E}- \\
01\end{array}$ & $9.03 \mathrm{E}-01$ & $3.50 \mathrm{E}-01$ & $6.13 \mathrm{E}-02$ & $2.57 \mathrm{E}+00$ & $\begin{array}{l}9.91 \mathrm{E}- \\
02\end{array}$ & $7.55 \mathrm{E}-01$ \\
\hline & Spleen & $8.44 \mathrm{E}-03$ & N.A. & $1.71 \mathrm{E}-01$ & N.A. & 4.94E-02 & $2.30 \mathrm{E}-02$ & $8.48 \mathrm{E}-03$ & $2.35 \mathrm{E}+00$ & $\begin{array}{c}1.93 \mathrm{E}- \\
01\end{array}$ & $5.37 \mathrm{E}-02$ \\
\hline & Salivary glands & $5.00 \mathrm{E}-01$ & $8.40 \mathrm{E}-03$ & $1.52 \mathrm{E}+02$ & $\begin{array}{c}8.49 \mathrm{E}- \\
02\end{array}$ & $1.02 \mathrm{E}-01$ & $6.46 \mathrm{E}-04$ & $8.40 \mathrm{E}-03$ & $1.35 \mathrm{E}+01$ & $\begin{array}{c}8.48 \mathrm{E}- \\
02\end{array}$ & $9.91 \mathrm{E}-02$ \\
\hline & Urinary bladder & $6.10 \mathrm{E}-01$ & $1.00 \mathrm{E}-02$ & $2.45 \mathrm{E}+00$ & $\begin{array}{c}9.64 \mathrm{E}- \\
02\end{array}$ & $3.53 \mathrm{E}-01$ & 4.71E-01 & $1.09 \mathrm{E}-02$ & $2.25 \mathrm{E}+00$ & $\begin{array}{c}1.16 \mathrm{E}- \\
01\end{array}$ & $3.03 \mathrm{E}-01$ \\
\hline & Left Colon/LLI & $3.02 \mathrm{E}-03$ & N.A. & $6.06 \mathrm{E}-02$ & N.A. & 4.98E-02 & $2.89 \mathrm{E}-03$ & $2.39 \mathrm{E}-03$ & $1.93 \mathrm{E}-01$ & $\begin{array}{c}1.10 \mathrm{E}- \\
01\end{array}$ & $3.67 \mathrm{E}-02$ \\
\hline & Right Colon/ULI & $5.00 \mathrm{E}-01$ & $9.67 \mathrm{E}-03$ & $1.19 \mathrm{E}+03$ & $\begin{array}{c}6.89 \mathrm{E}- \\
02\end{array}$ & $1.41 \mathrm{E}-01$ & $6.37 \mathrm{E}-03$ & $3.60 \mathrm{E}-03$ & $8.75 \mathrm{E}-02$ & $\begin{array}{c}8.75 \mathrm{E}- \\
02\end{array}$ & $1.14 \mathrm{E}-01$ \\
\hline & $\begin{array}{l}\text { Remainder of } \\
\text { body }\end{array}$ & $6.23 \mathrm{E}-01$ & N.A. & $1.57 \mathrm{E}-01$ & N.A. & $3.95 \mathrm{E}+00$ & $6.45 \mathrm{E}-01$ & 7.63E-03 & $1.75 \mathrm{E}-01$ & $\begin{array}{c}2.47 \mathrm{E}- \\
02\end{array}$ & $3.99 \mathrm{E}+00$ \\
\hline \multirow{3}{*}{ 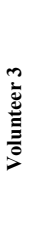 } & Liver & $6.85 \mathrm{E}-02$ & N.A. & $1.21 \mathrm{E}-01$ & N.A. & $5.65 \mathrm{E}-01$ & $6.28 \mathrm{E}-02$ & $6.20 \mathrm{E}-03$ & $1.32 \mathrm{E}-01$ & $\begin{array}{c}5.89 \mathrm{E}- \\
02\end{array}$ & $5.81 \mathrm{E}-01$ \\
\hline & Kidney & $1.00 \mathrm{E}+00$ & $7.00 \mathrm{E}-02$ & $1.99 \mathrm{E}+00$ & $\begin{array}{l}5.32 \mathrm{E}- \\
02\end{array}$ & $1.82 \mathrm{E}+00$ & $1.79 \mathrm{E}+00$ & $8.59 \mathrm{E}-02$ & $2.66 \mathrm{E}+00$ & $\begin{array}{c}7.35 \mathrm{E}- \\
02\end{array}$ & $1.84 \mathrm{E}+00$ \\
\hline & Small Intestine & $2.65 \mathrm{E}-02$ & N.A. & $1.23 \mathrm{E}-01$ & N.A. & $2.15 \mathrm{E}-01$ & $2.14 \mathrm{E}-02$ & 4.15E-03 & $1.08 \mathrm{E}-01$ & $\begin{array}{c}1.08 \mathrm{E}- \\
01\end{array}$ & $2.37 \mathrm{E}-01$ \\
\hline
\end{tabular}




\begin{tabular}{|c|c|c|c|c|c|c|c|c|c|c|c|}
\hline & Spleen & $1.05 \mathrm{E}-02$ & N.A. & $1.38 \mathrm{E}-01$ & N.A. & $7.65 \mathrm{E}-02$ & $1.64 \mathrm{E}-03$ & $9.00 \mathrm{E}-03$ & 1.37E-01 & $\begin{array}{c}1.36 \mathrm{E}- \\
01\end{array}$ & $7.81 \mathrm{E}-02$ \\
\hline & Salivary glands & $5.00 \mathrm{E}-01$ & $6.35 \mathrm{E}-03$ & $2.97 \mathrm{E}+02$ & $\begin{array}{l}7.92 \mathrm{E}- \\
02\end{array}$ & $8.18 \mathrm{E}-02$ & $6.46 \mathrm{E}-04$ & $6.34 \mathrm{E}-03$ & $1.38 \mathrm{E}+01$ & $\begin{array}{l}7.75 \mathrm{E}- \\
02\end{array}$ & $8.19 \mathrm{E}-02$ \\
\hline & Urinary bladder & $5.00 \mathrm{E}-01$ & $1.60 \mathrm{E}-03$ & $1.51 \mathrm{E}+02$ & $\begin{array}{c}3.62 \mathrm{E}- \\
02\end{array}$ & $4.75 \mathrm{E}-02$ & $5.23 \mathrm{E}-04$ & $1.58 \mathrm{E}-03$ & $1.59 \mathrm{E}+01$ & $\begin{array}{c}3.07 \mathrm{E}- \\
02\end{array}$ & $5.15 \mathrm{E}-02$ \\
\hline & Left Colon/LLI & $2.80 \mathrm{E}-03$ & N.A. & $1.12 \mathrm{E}-01$ & N.A. & $2.49 \mathrm{E}-02$ & $7.31 \mathrm{E}-04$ & $1.83 \mathrm{E}-03$ & 8.07E-02 & $\begin{array}{l}8.07 \mathrm{E}- \\
02\end{array}$ & $3.17 \mathrm{E}-02$ \\
\hline & Right Colon/ULI & $6.79 \mathrm{E}-03$ & N.A. & $1.05 \mathrm{E}-01$ & N.A. & $6.45 \mathrm{E}-02$ & $2.48 \mathrm{E}-03$ & $3.14 \mathrm{E}-03$ & $7.21 \mathrm{E}-02$ & $\begin{array}{c}7.22 \mathrm{E}- \\
02\end{array}$ & $7.79 \mathrm{E}-02$ \\
\hline & $\begin{array}{l}\text { Remainder of } \\
\text { body }\end{array}$ & $6.13 \mathrm{E}-01$ & N.A. & $1.32 \mathrm{E}-01$ & N.A. & $4.64 \mathrm{E}+00$ & $4.98 \mathrm{E}-01$ & $1.05 \mathrm{E}-01$ & $1.26 \mathrm{E}-01$ & $\begin{array}{c}1.27 \mathrm{E}- \\
01\end{array}$ & $4.78 \mathrm{E}+00$ \\
\hline \multirow{9}{*}{ 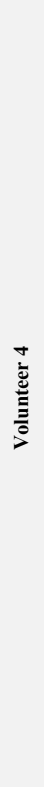 } & Liver & $9.38 \mathrm{E}-02$ & N.A. & $1.37 \mathrm{E}-01$ & N.A. & $6.86 \mathrm{E}-01$ & $8.19 \mathrm{E}-02$ & $1.35 \mathrm{E}-02$ & $1.58 \mathrm{E}-01$ & $\begin{array}{c}7.44 \mathrm{E}- \\
02\end{array}$ & $7.00 \mathrm{E}-01$ \\
\hline & Kidney & $7.13 \mathrm{E}-01$ & $7.00 \mathrm{E}-02$ & $1.80 \mathrm{E}+00$ & $\begin{array}{c}4.32 \mathrm{E}- \\
02\end{array}$ & $2.02 \mathrm{E}+00$ & $1.92 \mathrm{E}+00$ & $1.01 \mathrm{E}-01$ & $3.19 \mathrm{E}+00$ & $\begin{array}{l}\text { 7.47E- } \\
02\end{array}$ & $1.95 \mathrm{E}+00$ \\
\hline & Small Intestine & $5.00 \mathrm{E}-01$ & $3.12 \mathrm{E}-02$ & $9.02 \mathrm{E}+02$ & $\begin{array}{l}9.94 \mathrm{E}- \\
02\end{array}$ & $3.14 \mathrm{E}-01$ & $2.36 \mathrm{E}-02$ & $7.55 \mathrm{E}-03$ & $9.93 \mathrm{E}-02$ & $\begin{array}{l}9.94 \mathrm{E}- \\
02\end{array}$ & $3.14 \mathrm{E}-01$ \\
\hline & Spleen & $1.81 \mathrm{E}-03$ & N.A. & $1.43 \mathrm{E}-01$ & N.A. & $1.26 \mathrm{E}-02$ & $3.82 \mathrm{E}-04$ & $1.74 \mathrm{E}-03$ & $1.79 \mathrm{E}+01$ & $\begin{array}{c}1.21 \mathrm{E}- \\
01\end{array}$ & $1.44 \mathrm{E}-02$ \\
\hline & Salivary glands & $5.00 \mathrm{E}-01$ & $8.50 \mathrm{E}-03$ & $6.59 \mathrm{E}+01$ & $\begin{array}{l}7.83 \mathrm{E}- \\
02\end{array}$ & $1.16 \mathrm{E}-01$ & $5.23 \mathrm{E}-04$ & $8.48 \mathrm{E}-03$ & $1.74 \mathrm{E}+01$ & $\begin{array}{l}7.67 \mathrm{E}- \\
02\end{array}$ & $1.11 \mathrm{E}-01$ \\
\hline & Urinary bladder & $3.73 \mathrm{E}-03$ & N.A. & $3.83 \mathrm{E}-02$ & N.A. & $9.75 \mathrm{E}-02$ & 4.71E-04 & $3.68 \mathrm{E}-03$ & $1.92 \mathrm{E}+01$ & $\begin{array}{l}3.45 \mathrm{E}- \\
02\end{array}$ & $1.07 \mathrm{E}-01$ \\
\hline & Left Colon/LLI & $4.53 \mathrm{E}-03$ & N.A. & $1.04 \mathrm{E}-01$ & N.A. & 4.33E-02 & $2.53 \mathrm{E}-03$ & $3.14 \mathrm{E}-03$ & $7.32 \mathrm{E}-02$ & $\begin{array}{l}7.31 \mathrm{E}- \\
02\end{array}$ & $7.75 \mathrm{E}-02$ \\
\hline & Right Colon/ULI & $1.62 \mathrm{E}-02$ & N.A. & $1.17 \mathrm{E}-01$ & N.A. & $1.38 \mathrm{E}-01$ & $7.22 \mathrm{E}-03$ & $5.59 \mathrm{E}-03$ & $6.87 \mathrm{E}-02$ & $\begin{array}{l}6.89 \mathrm{E}- \\
02\end{array}$ & $1.86 \mathrm{E}-01$ \\
\hline & $\begin{array}{c}\text { Remainder of } \\
\text { body }\end{array}$ & $6.09 \mathrm{E}-01$ & N.A. & $1.33 \mathrm{E}-01$ & N.A. & $4.59 \mathrm{E}+00$ & $4.98 \mathrm{E}-01$ & $9.62 \mathrm{E}-02$ & $1.23 \mathrm{E}-01$ & $\begin{array}{c}1.24 \mathrm{E}- \\
01\end{array}$ & $4.82 \mathrm{E}+00$ \\
\hline
\end{tabular}




\section{Graphical abstract}

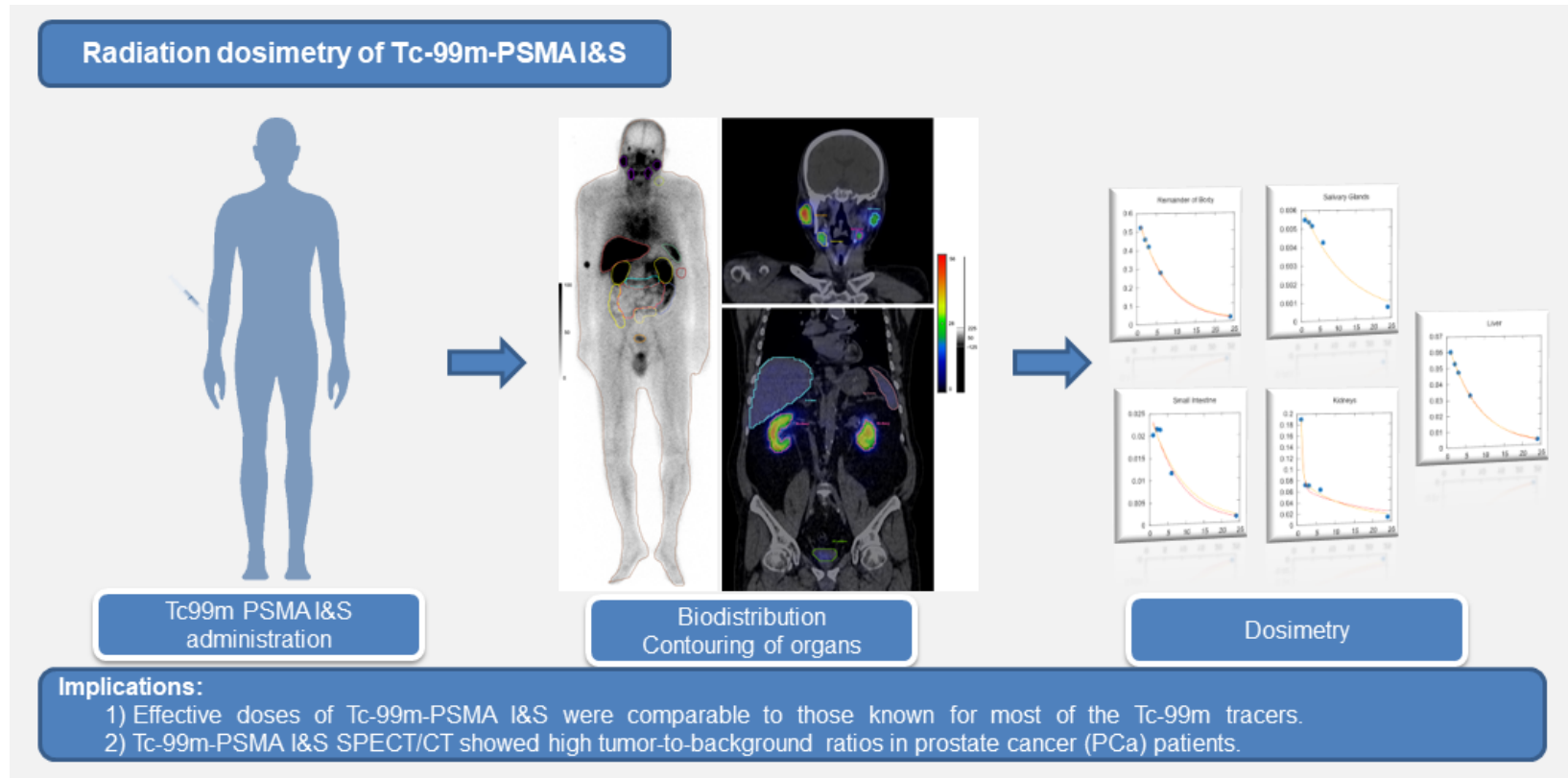

